\title{
LACTIC ACIDOSIS WITH NECROTIZING ENCEPHALOPATHY IN TWO SIBS
}

\author{
BY \\ HELEN E. WORSLEY, R. W. BROOKFIELD, J. S. ELWOOD*, R. L. NOBLE, \\ and W. H. TAYLOR $\dagger$ \\ From the Royal Liverpool Children's Hospital, and the Department of Chemical Pathology, Liverpool
}

(RECEIVED FOR PUBLICATION FEBRUARY 8, 1965)

The plasma lactate concentration is raised physiologically, during muscular exertion, and sometimes in diseases associated with demonstrable hypoxaemia, such as peripheral circulatory failure, severe shock, acute bronchial asthma, and obstructive emphysema. The plasma lactate level is also significantly raised in respiratory alkalosis arising from primary hyperventilation, and often in metabolic alkalosis. When there is alkalosis, there is usually no hypoxaemia, and the plasma concentration of pyruvate, the immediate precursor of lactate, is also proportionally raised. Gevers and Dowdle (1963) have shown that alkaline conditions stimulate the glycolytic rate in vitro of rat liver and kidney slices and that the effect is exerted at a stage or stages proximal to the dehydrogenation of triosephosphate.

A distinction has thus been drawn (Huckabee, 1961) between the alkalotic and the hypoxaemic group, for in the latter 'excess' lactate, relative to pyruvate, is found. 'Excess' lactate is defined as, (Ln-Lo)-(Pn-Po) (Lo/Po),

where $\mathrm{Ln}$ and $\mathrm{Pn}$ are the actual values of lactate and pyruvate, respectively, and Lo and Po, the expected respective normal values.

Recently, a syndrome of lactic acidosis has been described (Huckabee, 1961; Daughaday, Lipicky, and Rasinski, 1962) in patients who have 'excess' lactate but apparently no hypoxaemia. The patients show hyperpnoea, dyspnoea, and metabolic acidosis, and have a poor prognosis. They present with a variety of diseases including poliomyelitis, gastric ulcer, coronary thrombosis, pneumonia, and nonketotic diabetic acidosis.

This paper describes two brothers who presented with identical clinical features of hyperpnoea, progressive ataxia, mental deterioration, loss of

\footnotetext{
* Present address: Department of Pathology, Altnagelvin Hospital, Londonderry, N. Ireland.

+ Correspondence about this paper should be addressed to W. $\mathbf{H}$. Taylor, Dept. of Chemical Pathology, United Liverpool Hospitals, Ashton Street, Liverpool 3.
}

scalp hair, and convulsions, and who each showed, at necropsy, degenerative changes in the central nervous system. One of the brothers was investigated biochemically and found to have a severe lactic acidosis, apparently of primary origin.

\section{Methods}

Blood pyruvate was estimated by the method of Friedemann and Haugen (1943), plasma lactate by that of Hullin and Noble (1953), and blood glucose by a glucose oxidase method (Marks, 1959). Chromatography of plasma organic acids was carried out by the procedures described by Smith (1960).

\section{Case Reports}

Case 1. A boy aged 17 months was referred to the out-patient department of the Royal Liverpool Children's Hospital on August 16, 1960, by Dr. J. Lawson. Six weeks previously, a few hours after an injection of poliomyelitis vaccine, there had been twitching of both sides of his body and one week previously he had begun to stagger. Hitherto he had walked well. The parents were alarmed because 7 years earlier an elder male sib (Case 2) had developed similar symptoms and had died. On examination the child appeared to be perfectly normal, but 9 days later, because the mother was convinced of the similarity of the symptoms to those of the dead child, admission was arranged.

The birth weight had been $7 \mathrm{lb}$. $(3,175 \mathrm{~g}$.) and the delivery normal. He first stood at 10 months, walked at 13 months, and spoke simple words at 16 months. He had had measles and rubella. His height was 33 in. $(84 \mathrm{~cm}$.) and his weight $27 \mathrm{lb} .14 \mathrm{oz} .(12 \cdot 6 \mathrm{~kg}$.). Physical examination again revealed no abnormality except that he appeared to walk with rather a wide base. In other respects examination of the nervous system yielded negative results. The plantar responses were flexor in type and the optic discs were normal.

During the next three weeks he developed a slight intention tremor, his gait became frankly unsteady and there were episodes of hyperventilation. The rate of respiration was increased and the depth very much so. He usually sat with his body leaning forward and with his head thrown slightly backward. He kept his mouth closed. He did not seem to be greatly distressed and 
continued to look about him, but he made no attempt to speak or to play. These episodes occurred spontaneously at rest and lasted for up to four hours. When hyperventilation was frequent, incoordination increased and he had difficulty in feeding himself. From time to time there were coarse spontaneous movements as well as an intention tremor. These involved all the limbs and the head and, on occasion, resembled a convulsion except that consciousness was not lost and the child was still able to drink. There was no tachycardia and his blood pressure remained normal. When hyperventilation was prolonged, his extremities were noted to be cold, cyanosed, and slightly oedematous. Rapid fluctuations in weight were not fully accounted for by variations in food intake.

Investigations. The haemoglobin concentration was $78 \%(11.6 \mathrm{~g} . / 100 \mathrm{ml}$.) of normal and the leucocytes numbered $8,000 / \mathrm{c} . \mathrm{mm}$., $67 \%$ being lymphocytes. The serum sodium, potassium, and protein levels were normal, but the plasma chloride level was often raised and varied from 102 to $115 \mathrm{mEq} / 1$. The plasma bicarbonate was low, varying from 12 to $19 \mathrm{mEq} / \mathrm{l}$. The urine contained a trace of protein and its $p H$ varied from $5 \cdot 5$ to $6 \cdot 5$ with low or absent bicarbonate. The serum phosphate level was low for a child of his age, being $3 \cdot 3-4 \cdot 0 \mathrm{mg} . / 100 \mathrm{ml}$. Liver function tests were normal. That the hyperventilation and lowered plasma bicarbonate arose from a metabolic acidosis was indicated by the acid urine and by estimations of the blood $p H$. A value of $p \mathrm{H} 7 \cdot 36$ was obtained at a time when the plasma bicarbonate was $19 \mathrm{mEq} / 1$., and another of $p \mathrm{H} 7 \cdot 28$ when the plasma bicarbonate was $13 \mathrm{mEq} / \mathrm{l}$. The serum glutamate-oxaloacetate and glutamate-pyruvate transaminase levels were raised, varying, respectively, from 185 to 360 units $/ 100 \mathrm{ml}$. (normal, 23-107) and from 195 to 600 units/100 ml. (normal, 22-110).

The CSF had a normal protein content $(40 \mathrm{mg} . / 100 \mathrm{ml}$.), and was under normal pressure. Dr. J. Rees Roberts reported that the electroencephalogram showed paroxysmal activity which was generalized and consistent with cerebral injury. An intravenous pyelogram pointed to normal structure and function. The skull and bony skeleton were radiologically normal, except that the boneage was estimated to be only 6-12 months.

The cause of the acidosis was next elucidated. Diabetes mellitus was excluded because the fasting blood sugar (95 mg./100 ml) and the glucose tolerance curve were normal and the urine was free from ketone bodies. The plasma ketonic acid concentration was normal $(20 \mathrm{mg} . /$ $100 \mathrm{ml}$.). Chromatography of the urine revealed a generalized aminoaciduria, but the plasma amino acid nitrogen level was not raised, nor was the plasma amino acid distribution unusual. Indoxyl sulphate, tryptophan, and indolyl acetic acid were present in the urine in normal amounts. Chromatography of the plasma for organic acids revealed no abnormal constituents, but it was noted that the spot for lactic acid developed quickly and appeared dense. The plasma lactate level was then estimated quantitatively on two occasions when the patient was fasting, and not in a hyperpnoeic attack. High values of $30.5 \mathrm{mg} . / 100 \mathrm{ml}$. and $38.7 \mathrm{mg} . / 100 \mathrm{ml}$. were obtained, compared with the normal range of 6-18 $\mathrm{mg} . / 100 \mathrm{ml}$. and with a value of $10.5 \mathrm{mg} . / 100 \mathrm{ml}$. for a normal fasting control. The blood pyruvate level was raised, values of $2 \cdot 1$ and $2.4 \mathrm{mg}$. $/ 100 \mathrm{ml}$. being found. The calculation for 'excess' lactate gave a value of $+0.33 \mathrm{mEq} / \mathrm{l}$., thus revealing no significant excess. During a hyperpnoeic attack the plasma lactate rose to $54 \mathrm{mg} . / 100 \mathrm{ml}$. (6.0 mEq/1.).

It was concluded that the patient suffered from a persistent lactic acidosis, exacerbations of which were responsible for the hyperpnoeic episodes. Associated with this was a renal aminoaciduria, and possibly phosphaturia, and a progressive lesion of the central nervous system.

Progress. The patient died 7 months after his first admission. His decline was progressive but with intermissions. He found it increasingly difficult to maintain his balance, even when sitting. The muscle tone appeared reduced, but the tendon jerks could still be elicited. The plantar responses became extensor. During the early stages of his illness he appeared in no way retarded, and often showed persistence in attempting to compensate for his lack of coordination. As time went on, increasing tremor impaired his movements and he was no longer able to feed himself. The periods of hyperventilation were more frequent and prolonged, and the associated twitching was often so severe as to resemble a convulsion. He drooled constantly, his skin became dry, and his hair began to fall out. His vision deteriorated and he was found to have developed bilateral primary optic atrophy. Ultimately he could not sit without support, was withdrawn from his surroundings, and stared vacantly or slept.

During these months, he was treated with antibiotics on numerous occasions because of intermittent respiratory infections, and with a vitamin B complex, containing aneurine, riboflavine, nicotinamide, and pyridoxine. The muscle twitchings were to some extent controlled by chloral hydrate. He was also given alkalinizing agents, at first sodium bicarbonate, and later sodium citrate. Although these partially corrected the acidosis biochemically, the clinical symptoms were not improved and the hyperpnoeic attacks persisted. At a later stage in the illness and in an attempt to inhibit the excess lactate production, sodium fluoride was given in a dosage of 6 mg. daily. An initial improvement was noted. The patient became more interested in his surroundings and attempted to play, to feed himself, and to stand. Yet the bouts of hyperpnoea persisted and the plasma lactate, after three weeks, was still high (41.4 mg./100 ml.). The fluoride was discontinued because of uncertainty as to its efficacy and in order to assess the effect of its withdrawal. His condition deteriorated further and 6 days later he died, being then 25 months old.

NeCropsy Findings. The fundus of the stomach was adherent to the diaphragm over an area $3 \mathrm{~cm}$. in diameter. Here the stomach wall, especially the mucosa, was thin and atrophic, but no ulceration had occurred. A gradual transition to normal was noted between this area and the adjacent normal mucosa. Histological examination showed the mucosa and muscularis to be thin and 


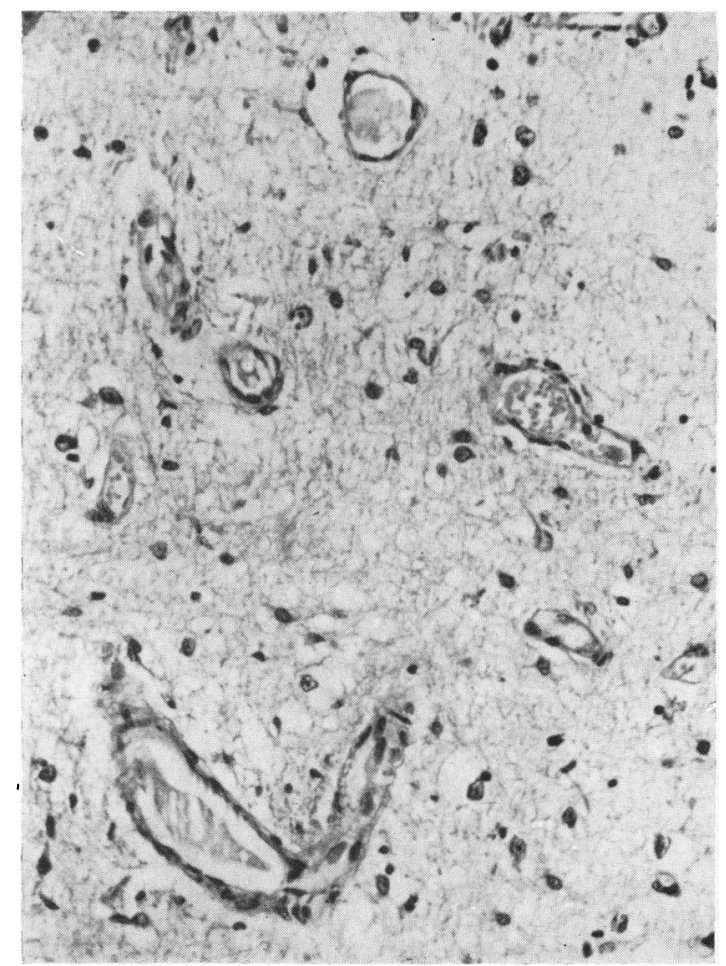

FIG. 1.-Mid-brain of Case 1 (H. and E. $\times$ 140.) Dilatation and hyalinization of capillaries in peri-aqueductal formatio reticularis.

slightly hyalinized but otherwise normal in structure in the adherent area.

After fixation, no striking macroscopic abnormality was seen in the brain and spinal cord. There was only slight prominence of the capillaries and doubtful sponginess of the white matter of the cerebellum. The other organs examined were normal.

Histological examination of the brain. In both the grey and white matter, symmetrical but non-systematized areas of degeneration of brain substance were present, in which surviving axons formed a loose network enmeshing remaining neurones. Fat-laden phagocytes were present near active lesions. Inflammatory cells were absent, and microglial and astrocytic activity was not a prominent feature, though occasionally present. There was loss of intensity of myelin staining with occasional globules of free fat and 'ballooning' of the myelin sheath, so that a clear zone appeared between it and the axon. This appearance we have called 'fenestration'. Such areas were devoid of significant gliosis.

Prominent, dilated, and engorged capillary blood vessels, with some hyalinization of their walls, accompanied this degeneration of the parenchyma and often covered a greater area than it. There was, however, little

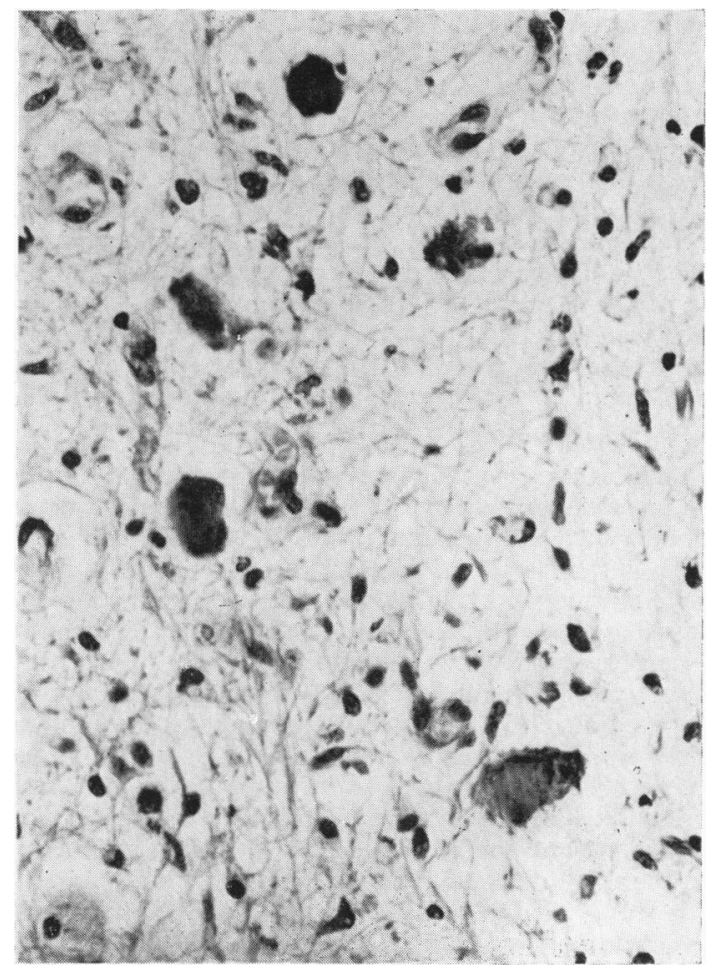

Fig. 2.-Medulla of Case 1. (H. and E. $\times$ 140.) Edge of cystic lesion in medial olivary nucleus showing vascularization and occasional fat-laden phagocyte. Note relative sparing of neurones and little gliosis.

endothelial proliferation or capillary budding. This appearance we have called 'vascularization' (Fig. 1).

In general, neuronal bodies showed few degenerative changes.

The tractus gracilis and cuneatus, at the level of the decussation of the pyramids in the medulla, showed vascularization and demyelination with abundant fatladen phagocytes. Cyst formation had occurred in these demyelinated areas. Similar changes were observed in the medial lemniscus at the level of the olive (Fig. 2). Advanced vascularization was evident in the formatio reticularis, especially about the central canal, the nuclei cuneatus and gracilis, the cranial nuclei XII, X, IX, and $\mathrm{V}$, and to a lesser extent in the olivary, dorsal, and medial olivary nuclei. Some loss of neurones was discernible in these nuclei.

In the pons, less marked demyelination and vascularization had occurred in the medial lemniscus than in the medulla. Advanced vascularization had occurred in the formatio reticularis and the cranial nuclei VIII, VII, VI, and V. These nuclei also showed some loss of neurones, with degenerative changes in those neurones remaining. The adjacent white matter showed fenestration.

In the mid-brain the caudal limit of the red nucleus was mildly vascularized, and the white matter of the rubro- 


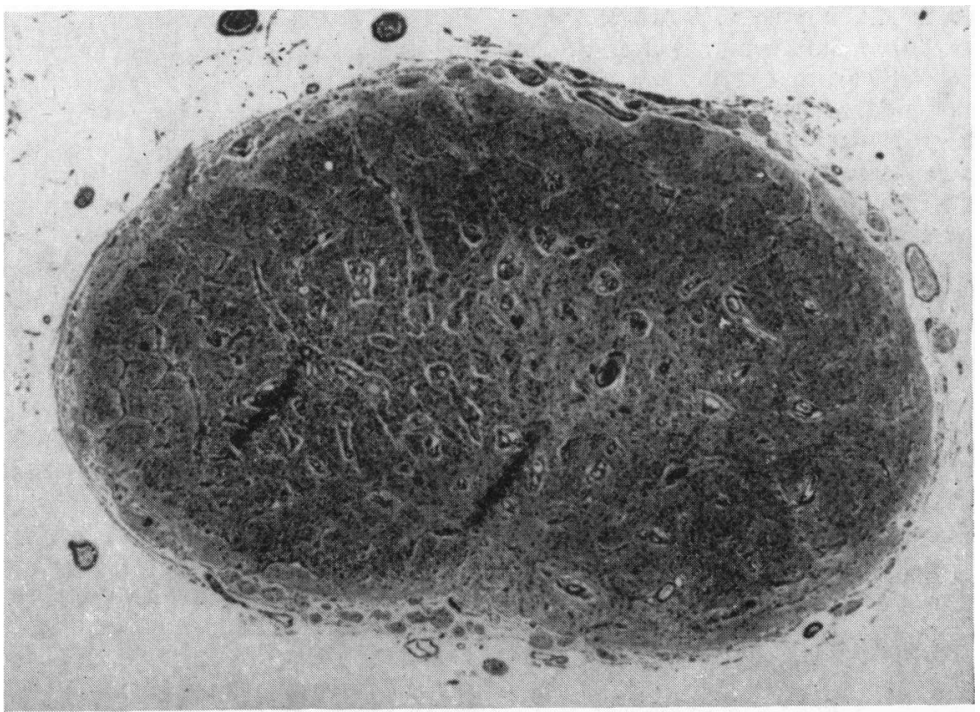

FIG. 3.-Optic nerve (H. and E. $\times$ 30.) of Case 1. Severe vascularization and demyelination of central part.

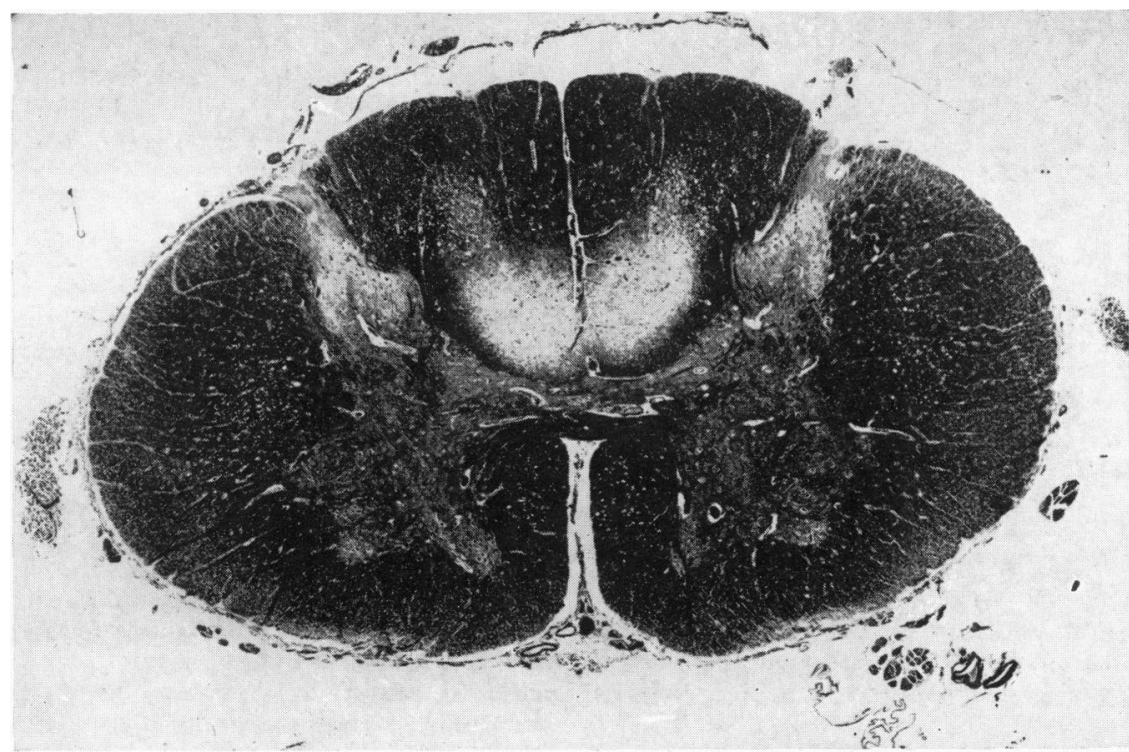

FIG. 4.-Thoracic spinal cord of Case 1. (Loyez. $\times 10$.) Demyelination of posterior white columns.

spinal tract, the superior cerebellar peduncle, and the medial longitudinal bundle was fenestrated. At this level the medial lemniscus was normal. Vascularization, loss of pigment, and mild degenerative changes were observed in the substantia nigra.

Advanced vascularization, some astrogliosis, and moderate neuronal degeneration had occurred in the tegmentum, throughout the formatio reticularis, the inferior, and superior colliculi, and the external geniculate bodies, and in cranial nucleus IV. Neuronal loss and vascularization involved the whole of each corpus mamillarium, and the remaining neurones showed degenerative changes.

In the cerebrum, vascularization was evident in the caudate, anterior, and lateral thalamic nuclei, and to a lesser extent in the putamen and medial thalamic nuclei; 
degenerative changes in the neurones, however, were sparse. The cerebral cortex and white matter of the hemispheres were essentially normal.

Reduction in number and marked degenerative changes in the Purkinje cells, and some vascularity and minor degenerative changes in the neurones of dentate nucleus were the only abnormalities seen in the cerebellum.

The optic nerves were severely vascularized and their central parts demyelinated (Fig. 3).

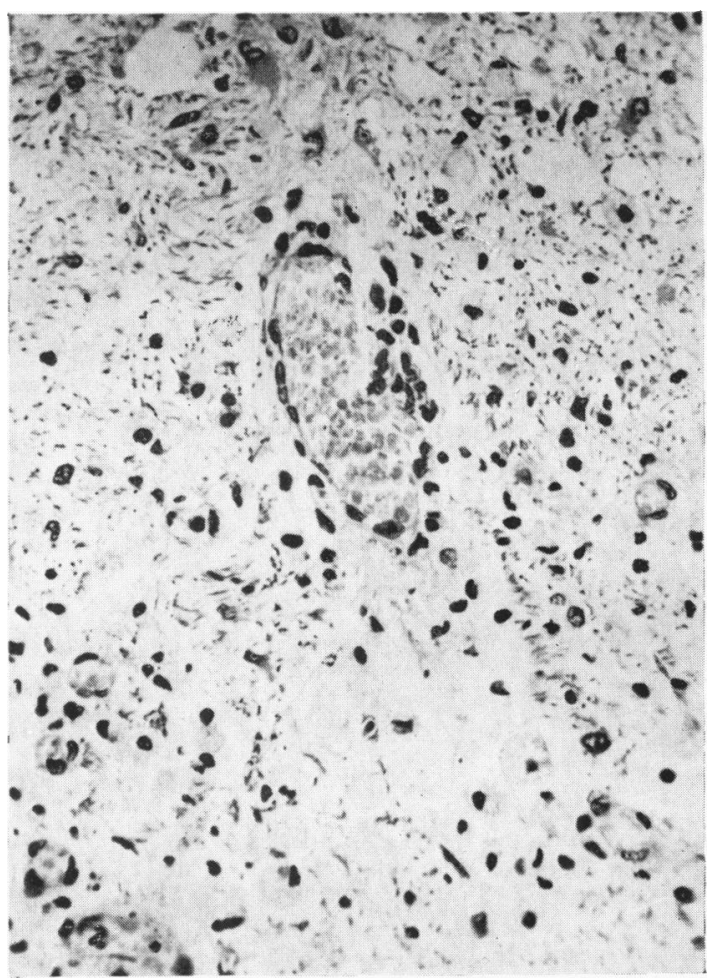

Fig. 5.-Thoracic spinal cord of Case 1. (H. and E. $\times 300$.) Demyelinated zone showing vascularization, some fat-laden phagocytes, but little gliosis.

Histological examination of spinal cord. Symmetrical lesions, detectable at most levels but maximal in upper thoracic and lower cervical segments, can be grouped as follows.

(a) Vascularization of the grey commissure and bases of the posterior horns. The anterior horns and remainder of the posterior horns were only involved in the upper thoracic segments, and at these levels only were minor degenerative changes noted in the anterior horn cells.

(b) At all levels, part of the lateral white columns, i.e. the spino-cerebellar and lateral cortico-spinal tracts and to a lesser extent the anterior spino-cerebellar tract, showed fenestration of the myelin.

(c) The most striking lesions were in the posterior columns (Fig. 4). In lumbar segments, vascularity and fenestration of myelin were apparent. In the lower thoracic segments, vascularity, demyelination, and some microglial proliferation were noted in about one-third of the posterior columns adjacent to the grey commissure. This lesion became more severe on ascending the cord and was maximal in upper thoracic and lower cervical segments, where abundant fat-laden phagocytes and free fat globules were also present, but there was surprisingly little gliosis (Fig. 5). At upper cervical levels only a small band of vascularization and demyelination passed through the central area of each posterior column, forming a V-shaped lesion with its apex between the posterior fissure and the grey commissure.

Case 2. The elder male sib of Case 1, the firstborn child of the family, was brought to the Royal Liverpool Children's Hospital on October 25, 1952. He was then 19 months old. Delivery had been normal and his weight at birth was $8 \frac{1}{2} \mathrm{lb}$. $(3,855 \mathrm{~g}$.). There was a history of muscular twitching between the ages of 3 to 10 months. Attacks had occurred approximately weekly, and each lasted for a few minutes. There was no tonic phase, but the child appeared to lose consciousness. From the age of 10 to 14 months, there were no further attacks, but thereafter episodes of twitching recurred, once more at about weekly intervals. He started to walk at the age of 14 months, and it was noticed that he was unsteady and fell easily. There had been no other illness.

Physical examination in the out-patient department showed a flabby child who appeared to be mentally retarded. The gait was unsteady and there was a tendency to fall backwards. Muscle tone and motor power seemed normal. The tendon reflexes were brisk and the plantar responses were flexor.

After admission to hospital, skull radiographs showed that there was no bony change or abnormal calcification. The electroencephalogram showed a moderate amount of delta activity, but the record was considered to be within the limits of the normal for his age. The CSF protein content was normal at $15 \mathrm{mg} . / 100 \mathrm{ml}$. The haemoglobin concentration was $88 \%(13.0 \mathrm{~g} . / 100 \mathrm{ml}$. $)$ and the white cells numbered 7,000 per c.mm. with a normal differential distribution. There was only one attack of twitching while he was in hospital. In it there were jerking movements of the right arm, trunk, and head; he did not react to stimuli and though sitting up he appeared to be unconscious. The twitching lasted for about 30 seconds and recurred about 5 minutes later.

He was seen to be hyperpnoeic for the first time when he attended at the out-patient department on February 3, 1953. There was mild bronchitis but no other change in the physical signs. Plasma electrolyte examinations revealed a raised serum sodium and chloride of 161 and $115 \mathrm{mEq} / 1$., respectively, while the plasma bicarbonate was low at $15 \mathrm{mEq} / \mathrm{l}$. The urine $p \mathrm{H}$ was 6 . There was no proteinuria, but a small amount of reducing substance was observed.

He was readmitted to hospital on March 24, 1953. Hyperventilation was now occurring frequently. His nutritional state remained good. He was very unsteady and could not stand, but sat without support and rocked to and fro. The left plantar response was doubtful, but 
otherwise the physical signs were unchanged. There were several attacks of twitching lasting up to half an hour. An air encephalogram was normal. The CSF was again normal.

At an out-patient attendance on April 21, 1953, it was noted that his hair had been falling out. On May 12, he was referred to the Neurological Department of the Royal Southern Hospital and was admitted for further study. Hyperventilation was still a marked feature, but it caused no distress. The deep reflexes were very brisk and this time both plantar reflexes were extensor. The optic discs were a little pale: vision appeared to be normal. He was drowsy and inattentive. Biochemical investigations revealed a low plasma bicarbonate of $15.5 \mathrm{mEq} / \mathrm{l}$. and a urinary $p \mathrm{H}$ of $5 \cdot 5$. Glucose was demonstrated in the urine on one occasion, and amino acid chromatography suggested a generalized aminoaciduria.

He was treated with an alkaline mixture containing potassium citrate and sodium bicarbonate. There was temporary clinical amelioration with some diminution of the hyperventilation, but there was no improvement in drowsiness. Fourteen days after this last admission he collapsed and died.

At necropsy, the lungs, heart, abdominal organs, kidneys, and brain were macroscopically normal. Histological examination of the kidney and brain revealed no abnormality at the time. New sections were cut 8 years later and were examined in the light of the findings from Case 1. The majority of these sections showed a normal brain, but in the midbrain there was vascularity and some neuronal degeneration of the reticular formation in the region of the aqueduct. The dentate nucleus showed marked neuronal degeneration and some demyelination of the white matter.

\section{Other Members of the Family}

The resting plasma lactate levels of the mother, father, and sister of the two patients were normal, being respectively $9 \cdot 2,13 \cdot 2$, and $12.0 \mathrm{mg} . / 100 \mathrm{ml}$. Both parents belonged to quite large family groups. There had been no early deaths in either group and no relatives had had illness in any way resembling that of the two children who are the subjects of this study.

\section{Lactic Acid Formation by the Erythrocytes}

Erythrocytes produce lactate readily by glycolysis from glucose, and much of the resting plasma lactate is thought to derive from this source. Since the resting plasma lactate level was raised in Case 1, the formation of lactate by the patient's erythrocytes was studied in vitro.

Heparinized blood was allowed to glycolyse, both in an atmosphere of nitrogen and in oxygen, in a Warburg apparatus at $37^{\circ} \mathrm{C}$. The rates of disappearance of glucose and formation of lactate were compared with those of blood from a normal control subject (aged 36 years). The oxygen uptake was also measured. The results are shown in Table 1. They indicate that after 105 minutes the blood glucose of the normal subject had been converted more or less quantitatively to lactic acid, both aerobically and anaerobically, for $41.5 \mathrm{mg}$. of glucose yielded $49 \cdot 7 \mathrm{mg}$. and $44 \cdot 7 \mathrm{mg}$. of lactic acid, respectively. There was thus an apparent 'nonglucose' lactate production of $3.2 \mathrm{mg} .100 \mathrm{ml}$. anaerobically, a value that is within the limits of experimental error. Aerobically, the oxygen uptake in 105 minutes was $3,133 \mu \mathrm{l} . / 100 \mathrm{ml}$. blood. Assuming that glucose was katabolized oxidatively, this uptake represents a glucose loss of $4 \cdot 2 \mathrm{mg}$. $/ 100 \mathrm{ml}$. The apparent aerobic 'non-glucose' lactate production was thus $49 \cdot 7-(41 \cdot 5-4 \cdot 2)=12 \cdot 4 \mathrm{mg} . / 100$ $\mathrm{ml}$. This is outside the limits of experimental error.

In the patient, on the other hand, a considerable anaerobic 'non-glucose' lactate production was revealed. Thus in 105 minutes only $12.5 \mathrm{mg}$. glucose $/ 100 \mathrm{ml}$. were katabolized anaerobically but $31.0 \mathrm{mg}$. lactate $/ 100 \mathrm{ml}$. were formed, - an excess of $18.5 \mathrm{mg} . / 100 \mathrm{ml}$. The oxygen uptake was $1,733 \mu \mathrm{l}$./ $100 \mathrm{ml}$. blood, equivalent to the katabolism of $2 \cdot 3$ mg. glucose $/ 100 \mathrm{ml}$. The lactate concentration of the blood increased aerobically by $33.5 \mathrm{mg} . / 100 \mathrm{ml}$. and the glucose concentration fell by $14 \cdot 3 \mathrm{mg} . / 100$ $\mathrm{ml}$. The apparent aerobic non-glucose lactate production was thus $33 \cdot 5-(14 \cdot 3-2 \cdot 3)=21 \cdot 5$ $\mathrm{mg} . / 100 \mathrm{ml}$. The formation of 'non-glucose' lactate, both aerobically and anaerobically, in the patient, was thus greatly in excess of that of the control.

The oxygen uptake of the blood of the patient was roughly the same as that of the control in terms of red cell content, being, respectively, $1,733 \mu \mathrm{l} . / 100 \mathrm{ml}$. with

TABLE 1

AEROBIC AND ANAEROBIC FORMATION OF LACTIC ACID IN THE BLOOD OF CASE 1, AFTER INCUBATION AT $37^{\circ}$ C. FOR 105 MINUTES

\begin{tabular}{|c|c|c|c|c|c|c|c|c|c|c|}
\hline \multicolumn{4}{|c|}{ Blood Glucose (mg./100 ml.) } & \multicolumn{3}{|c|}{ Blood Lactate (mg./100 ml.) } & \multirow{3}{*}{$\underset{\substack{\text { Haema- } \\
\text { tocrit }}}{\text {. }}$} & \multirow{3}{*}{$\begin{array}{c}\text { Oxygen } \\
\text { Uptake } \\
(\mu 1 . / 100 \mathrm{ml} .)\end{array}$} & \multirow{2}{*}{\multicolumn{2}{|c|}{$\begin{array}{c}\text { Lactate Production } \\
(\mathrm{mg} . / 100 \mathrm{ml} .) \\
\text { per } 1 \% \text { Haematocrit in }\end{array}$}} \\
\hline & \multirow{2}{*}{ Initial } & \multicolumn{2}{|c|}{ After Incubation in } & \multirow{2}{*}{ Initial } & \multicolumn{2}{|c|}{ After Incubation in } & & & & \\
\hline & & $\mathrm{N}_{2}$ & $\mathrm{O}_{2}$ & & $\mathbf{N}_{2}$ & $\mathrm{O}_{2}$ & & & $\mathbf{N}_{2}$ & $\mathrm{O}_{2}$ \\
\hline Control & & 0 & 0 & $12 \cdot 3$ & 57 & 62 & 48 & 3,133 & 0.93 & $1 \cdot 03$ \\
\hline & $\begin{array}{l}40 \\
34 \\
32 \cdot 5\end{array}$ & $\begin{array}{c}19 \\
22 \cdot 5\end{array}$ & 19 & $28 \cdot 5$ & $59 \cdot 5$ & 62 & 28 & 1,733 & $1 \cdot 11$ & $1 \cdot 20$ \\
\hline
\end{tabular}


a corrected haematocrit of $28 \%$ and $3,133 \mu \mathrm{l} . / 100 \mathrm{ml}$. with a corrected haematocrit of $48 \%$. The rate of anaerobic katabolism of glucose was, however, slower in the patient's blood per volume of red cells than in the control, being $12.5 \mathrm{mg} . / 100 \mathrm{ml}$. in 105 minutes with a haematocrit of $28 \%$ compared with at least $41.5 \mathrm{mg} . / 100 \mathrm{ml}$. with a haematocrit of $48 \%$ in the control. Of the total blood glucose available for katabolism in the patient, relatively more was in the plasma, $72 \%$ as against $52 \%$ when compared with the normal control, so that the diminished rate of glucose katabolism might be related to the necessity for the plasma glucose to enter the relatively small number of cells. On the other hand the rate of lactate production by the patient's cells, anaerobically, was $19 \%$ greater per unit volume of red cells than that of the control and $17 \%$ greater aerobically. However, as all the glucose of the normal subject was katabolized, his true rate of lactate production might have been higher.

In order to confirm that the patient's erythrocytes were forming lactate more readily than normal erythrocytes, the experiment set out in Table 2 was carried out, using a second normal subject (aged 33 years). The erythrocytes from each subject were

TABLE 2

PRODUCTION OF LACTIC ACID, ANAEROBICALLY, BY THE ERYTHROCYTES OF CASE 1 COMPARED WITH THOSE OF NORMAL CONTROL

\begin{tabular}{|c|c|c|c|}
\hline \multirow{2}{*}{ Incubation Mixture } & \multicolumn{3}{|c|}{ Lactic Acid Content (mg./100 ml.) } \\
\hline & $\begin{array}{c}\text { Before } \\
\text { Incubation }\end{array}$ & $\begin{array}{c}\text { After } \\
\text { Incubation }\end{array}$ & Difference \\
\hline $\begin{array}{l}\text { Patient's cells, } 3 \mathrm{ml} . \ldots \\
\text { Patient's plasma, } 3 \mathrm{ml} \text {. }\end{array}$ & $22 \cdot 7$ & $43 \cdot 3$ & $20 \cdot 6$ \\
\hline $\begin{array}{l}\text { Control cells, } 3 \mathrm{ml} . \\
\text { Control plasma, } 3 \mathrm{ml} \text {. }\end{array}$ & $13 \cdot 2$ & $31 \cdot 0$ & $17 \cdot 8$ \\
\hline $\begin{array}{l}\text { Patient's cells, } 3 \mathrm{ml} . \\
\text { Control plasma, } 3 \mathrm{mi} \text {. }\end{array}$ & $12 \cdot 8$ & $32 \cdot 6$ & $19 \cdot 8$ \\
\hline $\begin{array}{l}\text { Control cells, } 3 \mathrm{ml} . \\
\text { Patient's plasma, } 3 \mathrm{ml} \text {. }\end{array}$ & $23 \cdot 0$ & $40 \cdot 6$ & $17 \cdot 6$ \\
\hline $\begin{array}{l}\text { Patient's cells, } 3 \mathrm{ml} . . \\
\text { Patient's plasma, } 3 \mathrm{ml} . \\
\text { DL-alanine } \equiv 50 \mathrm{mg} . / 100 \mathrm{ml} .\end{array}$ & $22 \cdot 7$ & $44 \cdot 3$ & $21 \cdot 6$ \\
\hline
\end{tabular}

separated from the plasma, washed in isotonic saline, and incubated with each plasma separately, under the same conditions at $37^{\circ} \mathrm{C}$. for 85 minutes. Differences of $p \mathrm{H}$ and bicarbonate concentration in the two samples of plasma appeared not to affect the rate of lactate production, for the patient's cells formed lactate equally rapidly with each plasma, and so did the erythrocytes of the control subject. However, the patient's cells produced $17 \%$ more lactate than did the control cells from the patient's plasma, and $11 \%$ more from the control plasma. It should be noted that the patient's resting lactate level was again raised.

These experiments, taken together, indicate that the patient's erythrocytes formed lactate more rapidly than did those of two normal subjects, but that not all of this lactate came from glucose. In an attempt to ascertain what other substances than glucose might be converted to lactate, the patient's cells were also incubated with DL-alanine, but a significant increase in lactate formation did not occur.

Subsequently it has been possible to repeat the experiment of Table 2 in a female patient aged 22 years complaining of muscular weakness, who had a high resting plasma lactate $(75.5 \mathrm{mg} . / 100 \mathrm{ml}$.) without recurrent attacks of acidosis or hyperpnoea. The cause of this hyperlactataemia is, as yet, unknown. The normal control was a woman of similar age. The patient's erythrocytes formed lactate at a rate identical with those of the control subject. It is unlikely, therefore, to be the general rule that the erythrocytes in hyperlactataemia produce lactate more rapidly than do normal erythrocytes. The aetiological significance of the increased rate of lactate production by the erythrocytes of Case 1 is thereby enhanced.

\section{Discussion}

Biochemical Features. Though there is no direck evidence of lactic acidosis in Case 2, the similar clinical presentation of the two cases, the similar biochemical findings, the similar clinical course, including loss of scalp hair, and the parents' early recognition of the onset of the disease in Case 1 , combine to suggest very strongly an identical and, therefore, familial condition. Neither parent, nor a female sib born between the two brothers, appear to be affected.

The differential diagnosis, biochemically, is essentially between primary lactic acidosis, and respiratory alkalosis from primary hyperventilation. The evidence supports the former diagnosis, for in both patients the urine was acid at rest and during the hyperpnoeic attacks, and in Case 1 the blood $p \mathrm{H}$ became more acid as the lactate level rose during hyperpnoea. In respiratory alkalosis both the blood and urinary $p \mathrm{H}$ would be expected to become more alkaline. Furthermore in neither patient did necropsy reveal any lesion in the brain that could specifically be held responsible for a primary hyperventilation syndrome.

The attacks of hyperpnoea seemed to arise, therefore, from intermittent sudden increases in lactic acid concentration in the plasma. The ataxia, hypotonia, and muscular tremor were present when 
there was little or no hyperpnoea, and did not result from hyperpnoea, though they were exacerbated by it. They thus represent a second feature of the syndrome, associated with the diffuse cerebral and cerebellar lesions. A third feature is the renal aminoaciduria and low serum phosphate. The occasionally raised plasma chloride must also be explained. It seems that the over-all acidosis was partly caused by lactate accumulation and partly also by chloride. In the absence of dietary loading of chloride, this hyperchloraemia is probably also a renal manifestation; though an acid urine was secreted, it seems as if the kidneys were not able to compensate fully for the increased lactic acid load, so that chloride was retained in exchange for lactate. Just as in renal acidosis of infants, the kidneys cannot cope with a normal anionic load, and hyperchloraemia ensues.

The in vitro studies upon glycolysis established that the patient's erythrocytes produced lactate more quickly than did those of two normal subjects, but that much of this lactate did not come from glucose. There are two possible explanations for this. The lactate might be formed from other substances than those of the glycolytic sequence, or there may be in the patient's erythrocytes an unusual distribution of intermediate compounds of the glycolytic sequence. Because of the raised amounts of transaminases in the plasma, the possibility that amino acids might act as lactate precursors was investigated, but the addition of alanine to the patient's erythrocytes in vitro (Table 2 ) did not significantly increase the yield of lactate. Furthermore, the patient's serum did not contain sufficient amino acids to account quantitatively for the 'non-glucose' lactate production. The key to the problem almost certainly lies in the specificity of the glucose oxidase method for blood glucose. By this method the patient's fasting blood glucose value was low $(33 \mathrm{mg}$. $/ 100 \mathrm{ml}$.), but by copper reduction methods, the fasting blood 'sugar' was normal (60 to $95 \mathrm{mg}$./100 ml.). The former method does not estimate the phosphorylated hexoses of the glycolytic sequence (glucose-6-phosphate, fructose-6-phosphate and fructose $1: 6$ diphosphate), but the latter method does. The second hypothesis, that in the patient a greater proportion of the total blood 'sugar' exists as hexose phosphates, rather than as glucose, would thus account for, (a) the 'non-glucose' lactate production, (b) the increased rate of lactate production demonstrated in vitro, and (c) the low true glucose level in the blood. The smaller but significant 'non-glucose' lactate production of normal subjects would also be explained as arising from the amounts of hexose phosphates present normally.
On this hypothesis the plasma pyruvate concentration should also be raised and this was found to be the case. The value for 'excess' lactate depends very much on the level of 'expected' value that is assumed. In our patient the 'excess' lactate was $+0.33 \mathrm{mEq} / \mathrm{l}$. which is not significant. Even if the higher values of American workers for Po and their lower values for Lo were used, the highest possible value for 'excess' lactate would be only $+2 \cdot 8 \mathrm{mEq} / 1$. This eliminates hypoxia as a cause of the raised lactate level, and suggests a rate of production of pyruvate greater than its rate of utilization, with its subsequent conversion to lactate.

There is no evidence to show that tissues other than erythrocytes contributed to the lactic acidosis, though the precipitation of a prolonged hyperpnoeic attack by mild exertion suggests that glycolysis in muscle might also have taken place at a faster rate than normal.

Only one infant with primary lactic acidosis has been described previously (Hartmann, Wohltmann, Purkerson, and Wesley, 1962). The patient was a female mongol who presented at the age of 2 months with attacks of 'heavy breathing', muscular weakness, and failure to gain weight. During the attacks she sometimes became unconscious, with laryngeal and bronchiolar spasm and asphyxial convulsions. Investigation showed that the resting plasma lactate was raised and that during the attacks there was severe acidaemia with the lactate concentration rising as high as $18.0 \mathrm{mEq} / 1$. (162 mg./100 ml.). There was also a hyperchloraemia. The attacks responded to treatment with sodium bicarbonate, calcium gluconate, and magnesium sulphate. The authors have investigated the aetiology of the lactic acidosis in some detail and have excluded circulatory failure, glycogen storage disease, and aneurine deficiency. They demonstrated an increased rate of glycolysis of heparinized whole blood, but have been unable to define the metabolic lesion more closely. Their patient is clearly very similar to our patients in many respects, but differs in that she is female, mongoloid, and slowly losing the metabolic abnormality. Nor did she exhibit the neurological lesions and the renal tubular defect.

Neurological Features. The striking vascularity of the lesions in Case 1 cannot be due to closer approximation of capillaries as a result of disappearance of the neural parenchyma, since it was often present in areas in which the normal structure was still recognizable. That the necrosis is dependent on an antecedent vascular abnormality is unlikely in view of the persistence of neurones in areas of gross 
destruction. The relative absence of gliosis may result from degenerative processes overtaking neuroglial formation as well as the parenchyma, as is seen in rapidly advancing cases of subacute combined degeneration of the cord. In more chronic cases, or following therapeutic arrest of the disease, gliosis is the rule.

The published material suggests that the condition of 'necrotizing encephalopathy' described by Leigh (1951), Feigin and Wolf (1954), Richter (1957), Ule (1959), Reye (1960), and Tuthill (1960) is similar to the neurological manifestations of Case 1 . Of 15 reported cases in infants, 11 were in males, and 4 in females. Tuthill (1960) describes twin boys, both of whom were affected, and 2 of Feigin and Wolf's cases were sibs. In Reye's case an older female sib had died at 2 years from a similar illness, and in Richter's Case 3, the child's mother, herself a physician, stated that her brother had died at 13 months from a disease which she considered similar to that of her son. In 6 of the reported cases there were one or more normal sibs.

The ages at death of the reported cases ranged from 7 months to $4 \frac{1}{2}$ years, with a mean of 21 months. The onset of symptoms varied from birth to 2 years, failure of mental and nervous development was prominent, and difficulty in deglutition and inability to sit or stand were frequent presenting symptoms. Motor weakness was present in 11, with ataxia in 6; 5 had defective pupillary reflexes, 4 were blind, and 4 were deaf. Cranial nerve palsies were common. In all, respiratory difficulties were present and often led to death. Convulsions were common. Symmetrical lesions were constantly found in the mesencephalic tegmentum, pons, and medulla; other sites were not constantly involved. Cord involvement was present in 5: in 4 of these there were severe changes in the posterior columns, especially the tractus gracilis, which increased on ascent and maximally involved the thoracic and cervical regions. Significantly, in none were the corpora mamillaria involved. These symmetrical lesions are of similar structure to those in our case.

The superficial similarity of the lesions to those of Wernicke's encephalopathy tempts one to incriminate an abnormality of aneurine metabolism. Some authors (Feigin and Wolf, 1954; Tuthill, 1960; Ule, 1959) have regarded necrotizing encephalopathy as the morphological equivalent in infants of Wernicke's encephalopathy, but the involvement of the substantia nigra and the invariable sparing of the corpora mamillaria and absence of haemorrhage distinguish the two conditions. In our cases the corpora mamillaria were severely involved, the substantia nigra was affected, and haemorrhage was absent.
It is, however, not justifiable to assume that a particular morphological picture represents only one pathogenesis. It may well be that the appearance in these cases is the response of the immature nervous system to a variety of toxic effects; for example, carbon monoxide poisoning in man and animals, and poisoning by quinoline derivatives in monkeys, both result in symmetrical necrotic lesions similar in morphology and distribution to those of 'necrotizing encephalopathy' (Richter, 1957).

Among all reports cited, the only hint of a metabolic abnormality was in Case 1 of Feigin and Wolf (1954). In this child, as in both of ours, a persistently low plasma bicarbonate was found (in a personal communication from Feigin, the $\mathrm{CO}_{2}$ combining power was stated to be $10.6 \mathrm{mEq} / \mathrm{l}$.).

Effects of Fluoride. The connexion between the biochemical abnormalities and the neurological features remains obscure. If the hypothesis of enhanced glycolysis with a dynamic excess of phosphorylated hexoses is correct, fluoride ought to help correct the metabolic abnormality and improve the clinical features. This happened to only a small extent, but it is arguable that the dose of fluoride was too small. Certainly if we were to see further examples of this metabolic abnormality, we would wish to observe the effect of fluoride in higher dosage and would recommend such a trial to others.

\section{Conclusion}

Our patients appear to afford the first-described example of familial lactic acidosis in infancy. The association with necrotizing encephalopathy indicates that lactate metabolism should be investigated in all patients in whom the latter diagnosis is made. The role of fluoride in treatment should be explored further.

\section{Summary}

Two brothers are described who presented during the second year of life with ataxia, muscle twitching, and intermittent hyperpnoea at rest. The condition progressed, with mental deterioration, loss of scalp hair, and death after about 6 months.

One child had widespread, symmetrical, degenerative lesions of the brain and spinal cord resembling those previously described in infants with 'necrotizing encephalopathy'. The histological lesions in the second child were similar, but not so marked, nor so widespread.

The intermittent hyperpnoea of one child, and possibly of both, resulted from spontaneous increases of lactic acid in the blood. The erythrocytes were able to form lactic acid by glycolysis at a rate faster 
than those of two normal subjects. It is suggested that the proportion of phosphorylated hexoses to free glucose in the blood may have been raised, thus partly accounting for the increased glycolytic rate.

There was also a renal aminoaciduria and a lowered serum phosphate concentration.

This is believed to be the first description of familial lactic acidosis in young children.

We wish to acknowledge the help given to us by Dr. R. R. Hughes, Dr. C. A. St. Hill, Dr. J. Lawson, Dr. J. Rees Roberts, Dr. R. W. Evans, Dr. D. Boulter, and the members of the laboratory staff who assisted with the biochemical and histological investigations. J.S.E. acknowledges gratefully a grant for technical assistance from the Research Fund of the Board of Governors of the United Liverpool Hospitals.

\section{REFERENCES}

Daughaday, W. H., Lipicky, R. J., and Rasinski, D. C. (1962). Lactic acidosis as a cause of nonketotic acidosis in diabetic patients. New Engl. J. Med., 267, 1010.

Feigin, I., and Wolf, A. (1954). A disease in infants resembling chronic Wernicke's encephalopathy. J. Pediat., 45, 243.
Friedemann, T. E., and Haugen, G. E. (1943). Pyruvic acid. II. The determination of ketoacids in blood and urine. $J$. biol. Chem., 147, 415.

Gevers, W., and Dowdle, E. (1963). The effect of pH on glycolysis in vitro. Clin. Sci., 25, 343.

Hartmann, A. F., Wohltmann, H. J., Purkerson, M. L., and Wesley, M. E. (1962). Lactate metabolism: studies of a child with a serious congenital deviation. J. Pediat., 61, 165.

Huckabee, W. E. (1961). Abnormal resting blood lactate. Amer. J. Med., 30, 833, 840.

Hullin, R. P., and Noble, R. L. (1953). The determination of lactic acid in microgram quantities. Biochem. J., 55, 289.

Leigh, D. (1951). Subacute necrotising encephalomyelopathy in an infant. J. Neurol. Neurosurg. Psychiat., 14, 216.

Marks, V. (1959). An improved glucose-oxidase method for determining blood, C.S.F. and urine glucose levels. Clin. chim. Acta, 4, 395.

Reye, R. D. K. (1960). Subacute necrotising encephalomyelopathy. J. Path. Bact., 79, 165.

Richter, R. B. (1957). Infantile subacute necrotizing encephalopathy with predilection for the brain stem. J. Neuropath. exp. Neurol., 16, 281.

Smith, I. (1960). Chromatographic and Electrophoretic Techniques, Vol. 1. Heinemann, London.

Tuthill, C. R. (1960). Der morphologische Wernicke-Komplex in frühem Kindesalter (Familiäre Erkrankung bei 7 Monate alten Zwillingen.) Arch. Psychiat. Nervenkr., 200, 520.

Ule, G. (1959). Über eine der Wernickeschen Pseudoencephalitis entsprechende Encephalopathie bei Kindern. Virchows Arch. path. Anat., 332, 204. 